\title{
Editorial
}

\section{Just how different are retail look-alikes from traditional me-toos?}

Throughout the summer of 1994, roughly 16 per cent of the British cola market was in the hands of a look-alike, Sainsbury's Classic Cola. Compared to the previous summer, Pepsi's share was down almost 2 per cent and Coca-Cola's had fallen over 8 per cent. In the following months, Sainsbury's Classic Cola was joined by Asda Cola, Safeway Cola, Virgin Cola and Woolworth's Genuine American Cola. Proof, if proof were needed, that retail look-alikes had become a serious threat to leading producers of branded goods.

With good reason, leading producers have been very concerned. They point out that retailers are confusing consumers by placing goods on their shelves which look like existing well-established brands. They argue that such blatant and deliberate attempts to cause confusion are both unfair and unjust, in that their investment in brand building activities is seriously undermined.

Sainsbury's is portrayed as one of the main culprits. Its Classic Cola is merely the most visible of a string of look-alike products. It has also been accused of introducing lookalike Marmite and Bovril, and has been chastised for launching an anti-dandruff shampoo, Headway, which bears a striking resemblance to Head \& Shoulders. Many would argue that its laundry detergent, Novon, is uncannily similar to Ariel. It seems as if Sainsbury's is set to undermine many of our favourite brands.

Sainsbury's, however, is not alone in its actions. In any Boots store the distinct similarity between Timotei (the very successful Elida Gibbs frequent-wash shampoo) and Mild \& Gentle (the Boots private label) be- comes immediately noticeable. A scan of the shelves shows that many of the Boots products look familiar - a disturbing prospect for the producers of leading brands.

Examples such as these give rise to the widespread belief that the growth of lookalikes is a new phenomenon that is leading to unprecedented levels of consumer confusion. But is this impression correct?

\section{IS THE GROWTH OF LOOK-ALIKES A NEW PHENOMENON?}

The received wisdom says 'yes'. Recently, look-alikes have been doing more than sailing very close to the wind - they have been blatantly infringing passing off laws. ${ }^{1}$ It is argued that these breaches of the law are very different from 'me-too-ism'. The difference is between claiming a work of art to be by Constable, and painting in the style of Constable - a distinction that was not lost when judging the competent, but fraudulent, artistry of Tom Keating.

Unfortunately, such neat distinctions are often hard to prove. It is significant that few cases come under judicial gaze. Most are never challenged or they are settled out of court. Examples in the marketplace are decidedly grey. The name, 'Mild \& Gentle', describes the effect, on hair, of a frequentwash shampoo, whereas the name 'Timotei' is evocative - there is a clear difference here. At best, Mild \& Gentle sounds like a crude me-too. Nevertheless, the familiar shape, colouring and market positioning reveal this to be a look-alike in all but name.

Given that there is nothing new about 'me-too-ism', and that some me-toos have 
always sailed close to the wind, perhaps all that we have with look-alikes are extreme instances of an old phenomenon: a case of light grey merging into dark grey.

\section{ARE CONSUMERS CONFUSED BY LOOK-ALIKES?}

Some consumers really do find it hard to distinguish look-alikes from brands. But are these consumers any more confused by look-alikes than by all the minor product modifications - new varieties, new flavours, new tastes, new packages, new textures - or by the growing number of runof-the-mill private labels that are available in our supermarkets?

Consider the laundry detergent market. Even without the presence of strong private labels, many consumers were becoming confused by the launch of biological and non-biological powders, liquids and powders, and 'power' and 'non-power' varieties of the leading brands Persil and Ariel. The launch of Novon may not have confused shoppers at Sainsbury's any more than they were already.

Consider the potential confusion arising from the growth of baking soda toothpaste in the British market. Arm \& Hammer should be leading this sub-market. After all, they are 'The Baking Soda Experts' of 150 years standing. Arm \& Hammer toothpaste, however, comes in regular and mint flavoured varieties in $50 \mathrm{ml}$ tubes which are wrapped in standard rectangular boxes. How is the consumer to distinguish this brand from Colgate and Macleans me-toos? Indeed, how is the consumer to know whether Colgate is following Arm \& Hammer or vice versa? Given the reputation of all three brands, which is the best buy, or are all three equally good? It is doubtful that the entry of private labels would cause significantly more confusion.

This potential for confusion has to be set against the fact that we are all very experi- enced buyers and users of packaged goods. Assume a consumer buys 50 items each week. This amounts to 26,000 purchases over ten years. Now assuming that, on average, each item is used five times (a can of beans will be used once, but a tube of toothpaste might be used 40 times), then the total number of consumption events is 130,000 . Whatever the exact number, it is clear that this shopper will be an expert consumer!

Faced with this wealth of experience, consumers can respond in two ways:

(1) If the purchase is important enough, the consumer will stop, read the cues (design, packaging, name, logo, etc), and make a considered decision. Anyone who carefully studies a pack of Mild \& Gentle soon realises it is a Boots' private label, and not Timotei. Considered decision-making is, invariably, more often associated with product category choices than with brand choices ('Do I need frequent-wash shampoo or an anti-dandruff variety?', as against 'Do I want Timotei or Mild \& Gentle?').

(2) If the purchase is not so important (because there is little risk attached to making a poor selection), it may be a matter of indifference whether a brand or a look-alike is bought. Probably the choice will be based on value-formoney considerations and situational factors.

Typically, the observed outcome of (1) and (2), over time, is a pattern of divided loyalty, or polygamy. A consumer who often buys Timotei (the 'favourite' brand) might also buy a Boots' look-alike or a Tesco private label, and an expensive salon shampoo. The underlying decision-process will be based on the interplay of considered reasons ('I buy different brands for different usage occasions' or 'I like some variety'), situational factors ('It was the only one in stock' or 'I 
was drawn to it on the shelf'), and valuefor-money considerations ('I bought it on offer').

Such an outcome should not be seen as consumer confusion. Rather, it is a reasonable coping strategy for consumers when they are confronted with the task of routine buying and when the choice alternatives are so similar.

\section{SHOULD WE BE CONCERNED BY LOOK-ALIKES?}

The answer very much depends on one's viewpoint. Established producers have been the most vocal in expressing their concerns, notably through the British Producers \& Brand Owners Group. This was especially the case prior to the enactment of the Trade Marks Act 1994. ${ }^{2,3}$ A vigorous response was to be expected.

It is perfectly rational to try to protect assets where millions of pounds have been invested to build brand equity, secure a customer franchise, and create memorable brand names, familiar logos, and distinctive packaging. Anything less than a vigorous response would be an admission of defeat.

Some producers have responded by rebranding their product range. ${ }^{4}$ Dulux, faced with so many copycat designs, is in the process of adopting a new livery which it sees as 'distinguishable and non-copyable'. But, for many producers, re-branding is hardly an option. Apart from being expensive, it carries the risk of undermining patterns of habitual buying - all the benefits of brand familiarity are endangered in one fell swoop. Babycham, to quote just one example, is a shadow of itself without Bambi - a key element of brand familiarity has been lost.

On the other hand, it is also true that many leading producers preside over very lucrative markets. The latest Marketing/Nielsen survey of Britain's biggest brands shows that Coca-Cola is worth over $£ 400 \mathrm{~m}$, Ariel and
Persil are each worth about $£^{240 m}$, and Nescafé almost $£^{200 m}$. It is hardly surprising that competitors and new entrants seek to encroach on these markets. It is instructive to remember how the successful launch of McVitie's HobNobs was almost de-railed by the spoiling tactics of Burtons, or how Sensodyne toothpaste came under threat when the majors re-positioned their toothpastes for people with sensitive teeth, or, even more recently, how the ' 2 in 1 ' shampoo and conditioner market - once the preserve of Proctor \& Gamble's Wash \& Go - is now under a direct assault from Elida Gibbs' Organics haircare range. The threat of me-toos will always hang over these profitable markets. This is in the nature of competition.

Indeed, one significant effect of the growth of look-alikes is that different producers are pitched against each other. For instance, most of the new colas (Sainsbury's Classic Cola, Safeway Cola, Virgin and Woolworth's) are supplied by Cott Corporation, an old-established bottling company that is mounting an assault on Coke and Pepsi markets across the globe. ${ }^{5}$ This is very much a competitive struggle among producers.

By comparison, retailers should be highly contented. They are seen as the obvious winners in any struggle for a share of the consumer's purse. However, their own position is not clear-cut.

Retailers are leading brand owners in their own right. Indeed, the very success of private labels (which now account for almost 40 per cent of packaged goods sales in Britain) and the growth of look-alikes is a reaffirmation of branding - not a negation of it. Moreover, as retailers move into this territory, they incur many of the attendant costs of brand management, in paying for design consultancies, conducting product tests, and supporting new launches with large advertising and promotion budgets. Individual supermarket chains are spending upwards of $£ 20 \mathrm{~m}$ a year on advertising alone, putting them among heavy spenders 
such as Cadburys, Pedigree Pet Foods and Brooke Bond.

It is not, however, in the interest of retailers to kill off leading brands. The consequence of, say, Pepsi being squeezed out of the cola market would be to reduce the bargaining power of retailers when negotiating with Coca-Cola or private label suppliers. Another consequence would be to force even more producers to appeal directly to their buyers - following the initiatives of companies such as Nestlé ('Casa Buitoni Club') and Heinz ('Heinz at Home' magazine).

Finally, we should not ignore the fact that retailers, as owners of major brands in their own right, are increasingly exposed to intense competition. They have to cope with 'me-too-ism' in a world where consumers typically patronise a repertoire of stores. For instance, the onslaught on major brands by Boots is second only to its recent shot across the bows of Body Shop with the launch of the 'Natural' and 'Global' collections. Sainsbury's 'Nature's Compliments' is encroaching on Body Shop too. This is not a peculiarly British phenomenon; the Body Shop has imitators from Australia (Red Earth) to the USA (Bath \& Body Works). These are certainly me-toos, if not blatant look-alikes.

We are forced to conclude that look-alikes are not so very different from old-style 'metoos' and 'copy-cats'. In practice there is little reason to suppose that consumers are any more confused by most look-alikes than by closely competing brands and private labels. Furthermore, many consumers will have purchase repertoires which will include all these types of product. It is natural for established producers to be concerned, and to seek protection, but their assets always have been under threat and will be for the foreseeable future.

\section{References}

(1) Lane, J. and King, W. (1994) 'A Professional Disagreement', Marketing, 21st July, pp. 18-19.

(2) Davies, I. (1994) 'The Great CocaCola Dispute: Look-alikes', The Journal of Brand Management, Volume 2,

Number 1, pp. 59-64.

(3) Davies, I. (1994) 'Review of the Trade Marks Act 1994', The Journal of Brand

Management, Volume 2, Number 2, pp. 125-132.

(4) Miles, L. (1994) 'Designing for Distinction', Marketing Business, September, pp. 33-5.

(5) (1994) 'Copy Cotting catches on', Marketing, 20th October, p. 17.

\author{
Mark Uncles
} Editorial Board 